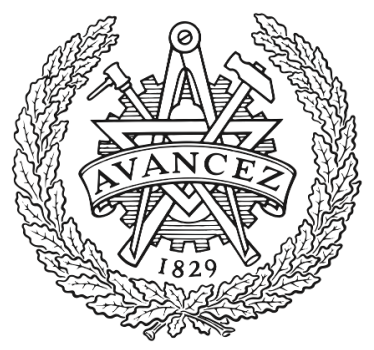

CHALMERS

UNIVERSITY OF TECHNOLOGY

\title{
Innovative prestressing method for externally bonded CFRP laminates without mechanical anchorage
}

Downloaded from: https://research.chalmers.se, 2023-04-26 14:20 UTC

Citation for the original published paper (version of record):

Yang, J., Haghani Dogaheh, R., al-Emrani, M. (2019). Innovative prestressing method for externally bonded CFRP laminates without mechanical anchorage. Engineering Structures, 197.

http://dx.doi.org/10.1016/j.engstruct.2019.109416

N.B. When citing this work, cite the original published paper. 


\section{Innovative prestressing method for externally bonded CFRP laminates without 2 mechanical anchorage}

3 Jincheng Yang, Reza Haghani, Mohammad Al-Emrani

4 Lightweight structures, Division of structural engineering, Chalmers University of Technology

5 Corresponding author: reza.haghani@chalmers.se

7 Published in Engineering Structures, Volume 197, 15 October 2019

$8 \quad$ https://doi.org/10.1016/j.engstruct.2019.109416

\section{Abstract}

Strengthening of reinforced concrete (RC) structures by externally bonded carbon fiber reinforced polymer (CFRP) laminates has been widely accepted as an effective and costefficient method. It is well known that advantages offered by the bonded CFRP laminates can be further increased by prestressing the laminates prior to bonding. Mechanical anchors are essential, in this case, to prevent debonding since interfacial stress at areas close to the ends of the strengthening laminate is several times higher than the strength of the concrete substrate. Common anchorage solutions often consist of bolted metallic plates to clamp the prestressed CFRP laminate. Besides labor-intensive installation operation, the anchor plates are vulnerable to galvanic corrosion, which further complicates the inspection and increases the maintenance costs. There are also doubts about the long-term performance of such anchorage systems as it highly depends on the quality of the adhesive layer between the plate and laminate, and the level of pre-tension in clamping bolts.

This paper presents the work conducted at Chalmers University of Technology on the development of an innovative prestressing method and a tool which allow for the application of prestressed CFRP laminates without mechanical anchors. The principles of the novel method and the prestressing system are explained. Experimental and numerical work carried out on an $\mathrm{RC}$ beam strengthened with this method is presented. Results indicate that CFRP laminates with high prestressing forces (approximately 30\% of CFRP tensile strength) can be safely anchored without the need for mechanical anchors. Numerical results based on finite element analyses show that the proposed prestressing method can reduce the interfacial shear stresses in the CFRP-concrete adhesive joint below the bond strength with reasonable safety margin.

\section{Keywords}

34 Carbon fiber reinforced polymer (CFRP); Prestressing; Externally bonded; Reinforced concrete (RC); Strengthening; Anchorage; Debonding; Experiment; Finite element 


\section{Introduction}

Since the mid-1980s, fiber-reinforced polymer (FRP) composites have been used for external strengthening of concrete [1], steel [2,3] and timber structures [4] and a great deal of research work has been devoted to different aspects of this technology in the past four decades [5-7]. Currently, FRP bonding has been widely accepted as an effective and cost-efficient upgrading technique in structural engineering. The technique offers several advantages such as easy and quick application, good durability and better strengthening effect compared to traditional methods. Flexural strengthening is the most common application in which FRP sheets or laminates are bonded to tensile parts of the structure and perform as "externally bonded reinforcement (EBR)" in interaction with internal steel reinforcement. To obtain the maximum strengthening effect, it is common to use carbon FRP (CFRP) laminates as they provide higher elastic modulus and better durability and fatigue characteristics compared to other types of FRP materials.

17 A major limitation when using externally bonded CFRP laminates for flexural strengthening is 18 the premature separation of the laminate from the structural member, known as "debonding".

19 Stress concentration due to shear lag effect at the ends of the bonded laminate, or intermediate 20 bending and shear cracks, often causes the debonding. Debonding is an unfavorable failure mode as it often takes place before the ultimate strength of the bonded laminate is reached. Studies show that, in most applications, only about 20-30\% of the CFRP laminate capacity can be utilized [1]. Studies show that introducing prestressing to CFRP laminates prior to bonding can improve the effect of strengthening and, at the same time, enhance the utilization of the CFRP laminate. Research in this area started in the early 1990s covering theoretical and experimental work [8-11]. As summarized in the review Aslam et al. [12], using prestressed CFRP laminates, instead of passive (non-prestressed) ones, can result in: (1) enhancing utilization of the strengthening laminate; (2) improving the fatigue strength of the strengthened structure; (3) enhancing the flexural capacity; and (4) improving the behavior of the strengthened member in serviceability limit state, such as delaying the initiation of cracks, increasing bending stiffness, and reducing crack width. There are mainly three alternatives to apply prestressed CFRP laminates as EBR: (1) introducing the prestress by cambering the structural member before bonding, (2) prestressing against an independent element, and (3) prestressing against the element to be retrofitted. The latter is the most practical to apply prestressing force. Prestressed CFRP reinforcement enables an active strengthening scheme meaning that it can cope with existing dead loads, in addition to extra imposed loads to be applied to the structure.

38 A problem associated with the application of bonded prestressed CFRP laminates is the rather high interfacial stresses built up in the bond line at areas close to the ends of the laminate. The high interfacial stresses (i.e. shear and peeling) are attributed to the so-called "shear lag effect", where the induced prestressing force in the laminate tends to transfer to the strengthened member over a short distance at the terminus of the laminate, which is referred to as "anchorage length" [13]. The sudden force transfer over this short length gives rise to interfacial stresses which are several times higher than the strength of concrete substrate and trigger the debonding failure [14]. Analyses show that rather low levels of prestressing force (ca. 5\% of the laminate ultimate strength) would create high enough interfacial shear stresses causing debonding. On 
1 the other hand, such low levels of prestressing would not be enough to make significant changes in the behavior of the strengthened structure compared to passive strengthening.

Anchorage of CFRP laminates is, therefore, an essential part of conventional prestressed EBR systems. Triantafillou et al. [14] studied the effects of prestressed CFRP sheets on RC beams and highlighted the need for anchorage at the CFRP ends to prevent the premature debonding. Mechanical anchors are the most common type for this purpose and often consist of metallic plates. The metallic anchor plate is the earliest form of anchorage devices studied by researchers and is considered to be the most effective when used for flexural strengthening [15].

However, mechanical anchors in general and metallic anchors in particular have several shortcomings, including (1) labor-intensive installation process involved with cutting and drilling concrete for installing metallic plates and bolts; (2) vulnerability of steel anchors to the corrosion during the service life; (3) restrictions in inspection due to lack of access and (4) aesthetic issues involved with using mechanical anchors. To cope with the corrosion problem, researchers have studied non-metallic anchors as alternatives, see for example [16,17]. Although the non-metallic alternatives can prevent some of the inherent shortcomings of the metallic anchors, they cannot deliver comparative anchorage capacity as metallic ones [15]. More information on existing anchorage solutions for EBR can be found in reviews by Grelle and Sneed [18] and Kalfat et al. [15].

In order to overcome the problems related to mechanical anchors, Stöcklin and Meier [19] proposed a gradient anchorage method, whose idea was to eliminate the need for mechanical anchors. The concept was based on the relationship between the gradient of axial force in the prestressed CFRP laminate and the magnitude of the interfacial shear along the adhesive bond line [20]. Using this method, it would be possible to control the interfacial stress by manipulating the axial force profile in the prestressed laminate. Obviously, to self-anchor the laminate without the aid of mechanical anchors, the interfacial shear stress should be reduced well below the shear strength of the concrete, as it is the weakest link in the joint. It is feasible to achieve this by gradually reducing the axial force in the prestressed laminate towards its ends. The decreasing gradient of the axial force is decided by the strength of the concrete substrate and design considerations. In practice, the gradient anchorage method was realized by releasing the prestressing force, in a number of steps, over a predefined length close to the ends of the laminate with the help of a computer-controlled system [21,22]. Meanwhile, a heating device was used to fast cure the epoxy in each step and prepare for the force release in the next step. Although this method succeeded to eliminate the mechanical end anchors, the procedure of applying the prestressing force into the laminate has to be conducted in multiple steps of force releasing and epoxy curing, which increases the operational complexity and time.

This paper presents an innovative method for the application of self-anchored prestressed CFRP laminates and demonstrates a prestressing tool developed for this purpose. The proposed method uses the same principle as the gradient anchorage method but focuses on simplifying the operation and shortening the application time without the involvement of complicated instruments. The research on the development of this method started in 2009 at Chalmers University of Technology in collaboration with Swedish Transport Administration [23]. To demonstrate the applicability of the method, this paper presents an experimental verification on an RC beam strengthened with this method. The prestressed CFRP laminate in the test was equipped with multiple strain gauges to monitor the strain magnitude and distribution during the prestressing and 6 days afterward. The prestressing loss and the laminate anchorage are discussed for the bonded CFRP laminate prestressed up to $30 \%$ of its ultimate strength. A finite element model was developed to further study the force transfer mechanism in the prestressing system and investigate the interfacial stresses in the CFRP-concrete adhesive joint. 


\section{$1 \quad 2$ Stepwise prestressing method}

\section{$2 \quad 2.1 \quad$ Principle}

3 The principle of the stepwise prestressing method is based on manipulating the profile of the 4 axial force along the prestressed CFRP laminate, in order to control the interface stresses that occur along the CFRP-concrete bond line after removing the prestressing system. This prestressing method is able to reduce the interfacial stresses (in shear and peeling) well below the strength of concrete substrates so that the prestressed laminate can be safely anchored relying on the strength of the CFRP-concrete bonded joint.
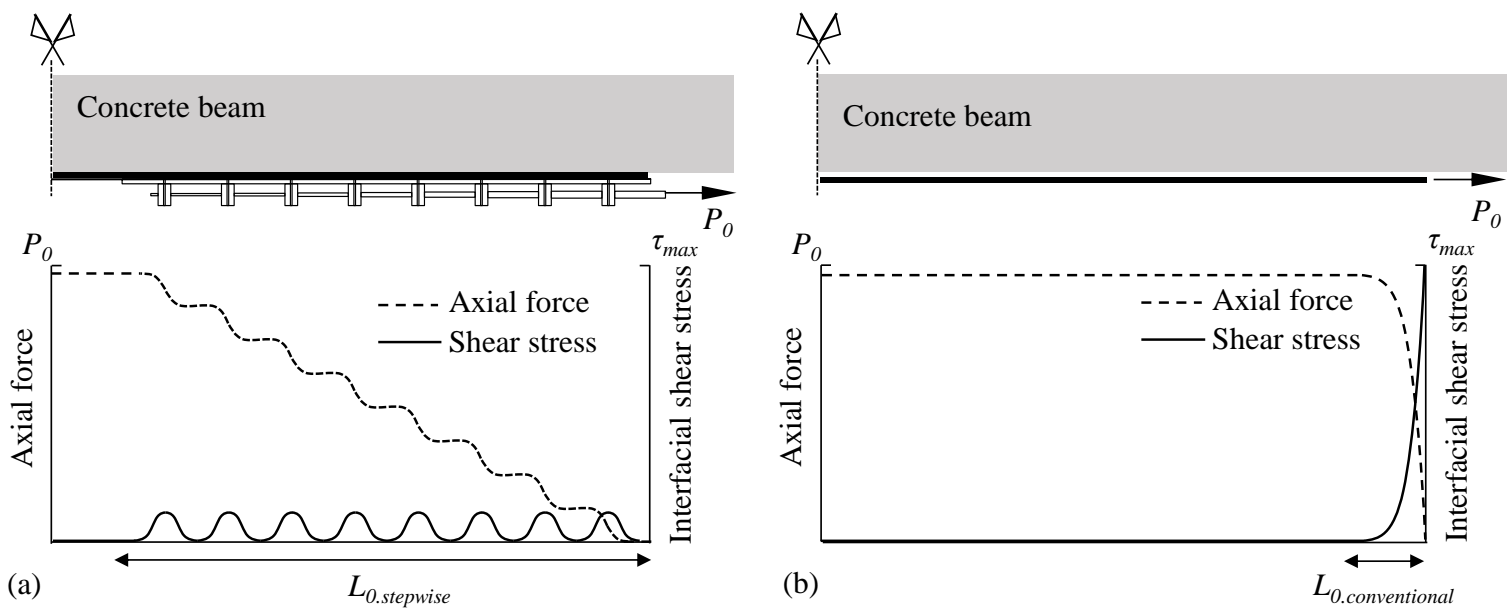

Figure 1. The fundamental difference between (a) stepwise prestressing method and (b) conventional prestressing method with regard to the axial force profile in the bonded CFRP laminate and the shear stress occurring in the adhesive layer; Lo.stepwise and Lo.conventional denote the anchorage lengths of bonded CFRP laminates using the corresponding application method.

Figure 1 illustrates the fundamental difference between the conventional and the stepwise prestressing methods with regard to the axial force profile in the prestressed CFRP laminate and the consequent interfacial stress distribution in the bond line after releasing the prestressing force $\mathrm{P}_{0}$. Unlike the conventional method where the laminate is pulled at two ends to create a constant axial force, the stepwise prestressing introduces a non-uniform axial force profile which is gradually built up towards the midspan of the laminate over a predefined length, referred to as "anchorage length". In this manner, the anchorage length can be designed and chosen to be "long enough" to reduce the interfacial shear stress in the CFRP-concrete adhesive joint to a desired level.

The magnitude of interfacial stress along the anchorage length is simply proportional to the gradient of the axial force in the laminate. Figure 2 illustrates the force equilibrium over a finite length of the bond between CFRP and concrete. The interfacial shear stress in Figure 2 can be expressed by Eq. 1 as:

$$
\tau=\frac{\Delta P}{b \cdot \Delta x}
$$

where $\mathrm{b}$ is the width of the CFRP laminate and $\mathrm{P}$ is the axial force at an arbitrary point of the prestressed laminate. Eq.1 shows that the magnitude of shear stress has a linear relationship with the gradient of the axial force in the laminate. It is worth mentioning that the interfacial peeling stress, i.e. normal stress perpendicular to the bond line, is a function of interfacial shear stress and thus influenced by the axial force gradient in the CFRP laminate as well [24]. 


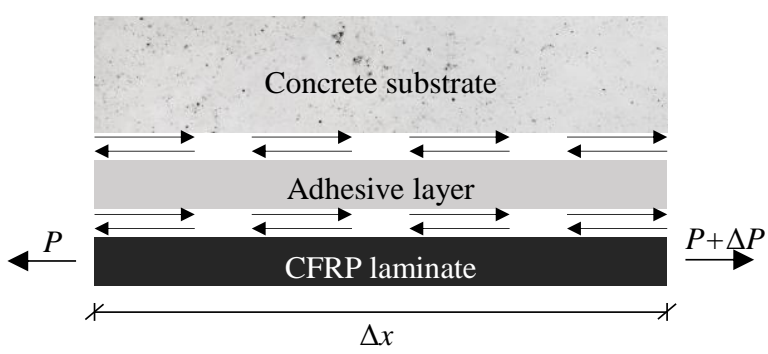

Figure 2. Force equilibrium over a finite length $\Delta x$ at an arbitrary point of the CFRP-concrete bonded joint

In order to control the interfacial stresses along the bond line, the gradient of the axial force in the CFRP laminate has to be reduced. In the stepwise prestressing method, this is achieved by dividing the total prestressing force $P_{0}$ into " $n$ " portions. Each portion is applied to a discrete point on the CFRP laminate along the anchorage length. Therefore, the axial force in the laminate would be built up in an accumulative manner as illustrated in Figure 3. The gradient of prestressing force and thus the magnitude of interfacial stresses can be controlled by selecting a suitable number of steps and the distance of the intervals. Theoretically, the anchorage length can be extended to the half-length of the CFRP laminate. However, from a practical point of view, it is preferred to minimize it to obtain a longer section of the CFRP with full prestressing force.

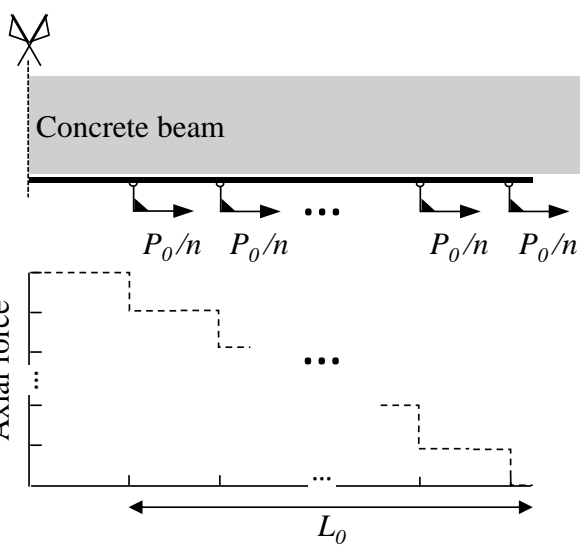

Figure 3. The concept of the stepwise prestressing method where the total prestressing force $P_{0}$ is divided into " $n$ " portions applied at discrete points along a CFRP laminate over the anchorage length $L_{0}$

\subsection{The prestressing system}

During developing the prestressing system for the stepwise method, two perquisites were kept in mind: (1) avoiding complicated or computer-controlled parts to minimize the risk of faults during operation, and (2) easy handling of the device and quick application. For this reason, a fully mechanical device, so called "prestressing tool", was developed. The concept of this tool is illustrated in Figure 4. It consists of a series of nodes (made of aluminum tabs) interconnected with springs (made of steel bars) of different stiffness constants. When the total prestressing force $P_{0}$ is applied to the first node (i.e. closest to the hydraulic jack), the mechanism of the tool allows for equal distribution of the force among the tabs and thus to the CFRP laminate. The axial stiffness of springs was designed so that each tab delivers an evenly portioned force of $\Delta P=P_{0} / n$ to the CFRP laminate. The main challenge, however, was how to connect the tabs to the CFRP laminate in practice. For this purpose, a plate made of glass fiber reinforced polymer (GFRP) was used as a connection medium. It was first bonded to the CFRP laminate and then fasten to the prestressing tool using embedded nuts in the GFRP connection plate. The GFRP connection plate not only facilitates the node-to-laminate connection but also helps to 
1 avoid stress concentration when the point load transmits from the tab to the CFRP laminate, 2 see Figure 4.

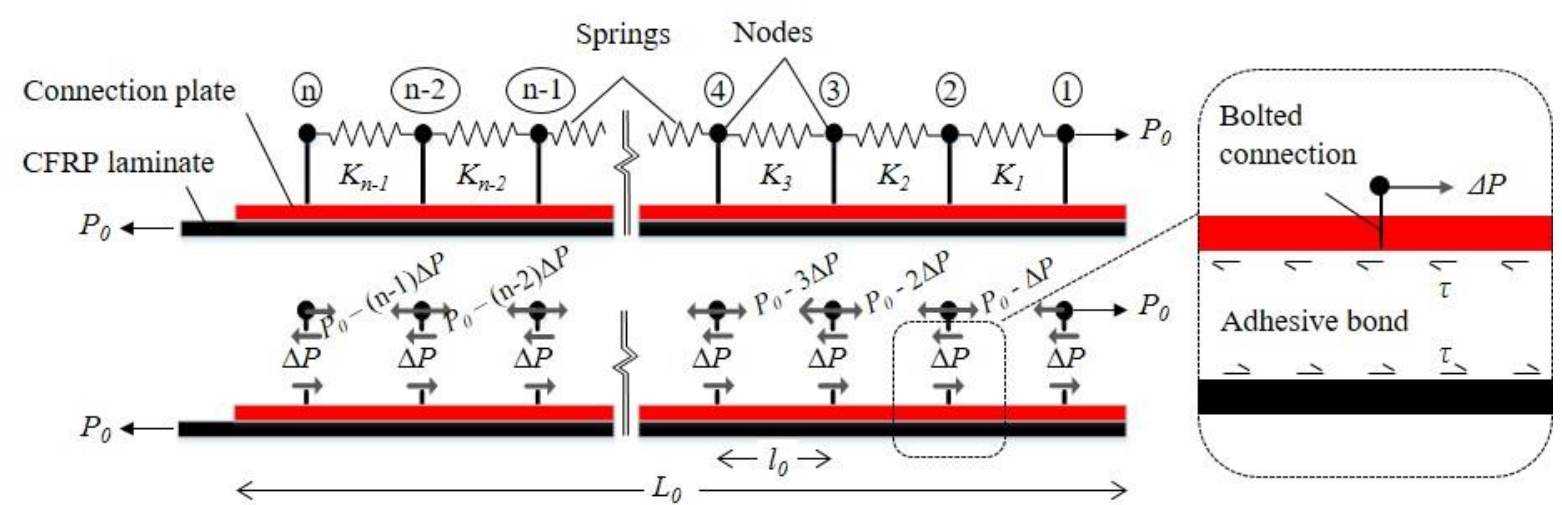

Figure 4. The concept of the prestressing tool illustrated using spring analogy

5 The prestressing tool is made with aluminum tabs as the nodes and high-strength steel bars as

6 the springs, see Figure 5. The cross-sections of the steel bars are designed with varying

7 diameters in order to provide the required axial stiffnesses. The connection plate made of GFRP

8 is $10 \mathrm{~mm}$ thick with the same width as the CFRP laminate and the length equal to the anchorage

9 length. The elastic modulus of the GFRP connection plate in the longitudinal direction is 6.2

$10 \mathrm{GPa}$ according to the laboratory test. The GFRP connection plate is bonded to CFRP laminate

11 at the workshop with a tailor-made epoxy adhesive and it remains on the CFRP laminate after

12 strengthening. The epoxy adhesive used between GFRP connection plate and the CFRP

13 laminate provides specific properties, including (1) satisfactory plastic behavior to avoid the

14 stress concentration along the bond line, (2) sufficient bond strength, and (3) acceptable resistance to creep deformation in order to avoid the significant loss of prestressing force during the curing of the adhesive between the CFRP and concrete substrate. To facilitate the connection to the prestressing tool, the GFRP connection plate is equipped with embedded hat nuts at identical intervals equal to the spacing of tabs. The embedded hat nuts enable a bolted connection between the GFRP connection plate and the tabs in the prestressing tool. As shown in Figure 5b, each tab is bolted using two M6 high strength bolts to the GFRP connection plate. In the design phase of the tool, the analysis indicated that a distance of $150 \mathrm{~mm}$ between two neighboring tabs would be optimum to dispense the load. 


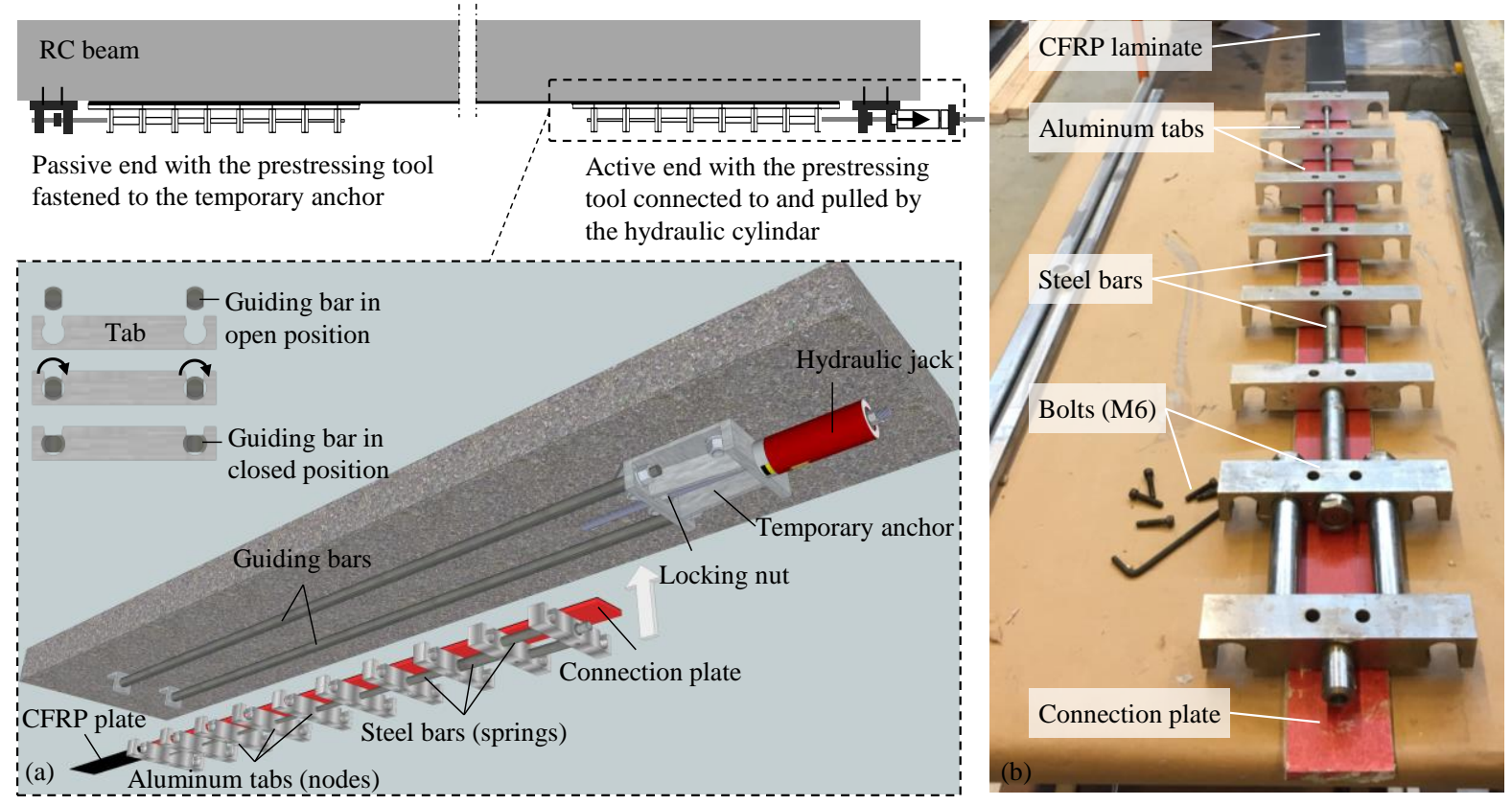

Figure 5. (a) The illustration of the prestressing system, and (b) the prestressing tool connected to a CFRP laminate via a connection plate made of GFRP

Besides the tool, the prestressing system includes other components to provide temporary support for the hydraulic jack during prestressing, see Figure 5a. It shows that two identical sets of the prestressing tool are installed at each end of the CFRP laminate. In the prestressing phase, the tool at the passive end is fastened to the temporary anchor, while the one at the active end is connected to the hydraulic jack. When the introduced maximum prestressing force reaches the design value, the locking nut at the active end is tightened to release the hydraulic jack and leave the bond line to cure. Most of the structural epoxy adhesives develop about $70 \%$ of their tensile capacity in room temperature after 24 hours, which is well above the concrete tensile strength. Therefore, 24 hours of curing time can be accepted as a safe choice before demounting the whole prestressing system. During the curing time, the structure can be in service since the prestressing force is safely anchored to the structure and the ultimate load capacity of the strengthened structure is not affected by the vibrations as demonstrated by Reed et al. [25]. In cases a shorter curing time is required, the accelerated curing technique aided by a heating element can be implemented to obtain enough bond capacity within a shorter time. Once the epoxy adhesive is sufficiently cured, the prestressing system can be safely demounted. The demounting procedure includes firstly opening the locking nut (see Figure 5a) and then removing the M6 bolts (see Figure 5b) to detach the prestressing tool from the connection plate. The connection plate will remain bonded on the CFRP plate after the operation.

\section{Experimental verification}

The proposed method was implemented to strengthen an RC beam in which the CFRP laminate was prestressed up to $100 \mathrm{kN}$. An epoxy adhesive was used to bond the laminate to the RC beam. In this experiment, the prestressing tool included 8 tabs (see Figure 5). The length of the connection plate was $1250 \mathrm{~mm}$ with a center-to-center distance of tabs equal to $150 \mathrm{~mm}$. Strains in the CFRP laminate were monitored using 19 strain gauges during prestressing operation and 144 hours after prestressing to study the axial force distribution in the laminate and the prestressing loss in the laminate. This beam was tested in the context of another experimental program whose result will be published separately. 


\subsection{Materials and specimen preparation}

A $4.5 \mathrm{~m}$ long RC beam with cross-sectional dimensions of $200 \times 300 \mathrm{~mm}^{2}$ was used in the experiment. The concrete beam was cast at the workshop using C35/45 concrete verified by the compressive test of concrete cylinders in the laboratory. Two steel reinforcement bars (K500C) with a diameter of $16 \mathrm{~mm}$ were placed in compression and tension zones. Transverse stirrups (K500C) with a diameter of $10 \mathrm{~mm}$ were equally placed at $75 \mathrm{~mm}$ over the entire beam length. The concrete cover was $70 \mathrm{~mm}$. The mechanical properties of the steel reinforcement were measured in the lab. The elastic modulus, the yield strength, and the ultimate strength of longitudinal bars were determined to be $201 \mathrm{GPa}, 510 \mathrm{MPa}$, and $618 \mathrm{MPa}$, respectively.

A unidirectional CFRP laminate (StoFRP ${ }^{\circledR}$ IM 80C), supplied by Sto ${ }^{\circledR}$ with a nominal crosssection of $80 \times 1.45 \mathrm{~mm}^{2}$ and a length of 3.8 meter, was used to strengthen the concrete beam. The mechanical properties of the laminate were obtained by testing coupons according to ASTM D3039 [26]. The elastic modulus and the ultimate tensile strain were measured to be $214 \mathrm{GPa}$ and $12.7 \%$, respectively.

A two-component epoxy adhesive (StoPox SK41), recommended by the supplier, was used to bond the CFRP laminate to the RC beam. The elastic modulus and the tensile strength of the epoxy were $7.1 \mathrm{GPa}$ and $34 \mathrm{MPa}$ after 14 days of curing in room temperature as reported by Heshmati et al. [27]. The design thickness of the adhesive bond line was $1 \mathrm{~mm}$. Poisson's ratio was assumed to be 0.2 for concrete and 0.3 for other materials.

\subsection{Prestressing the CFRP laminate}

Components of the prestressing system illustrated in Figure 5 will be referenced in this section. The process of applying the stepwise prestressing method includes the following steps in brief:

1. Install the temporary anchors on both the active and the passive ends;

2. Prepare the concrete surface according to recommendations in available guidelines. The surface of the beam in the experiment was ground with an angle grinder followed by compressed air and vacuum cleaning;

3. Mount the prestressing tool to CFRP at each end via the connection plate;

4. Apply the epoxy adhesive on the surface of the concrete and place the CFRP laminate (attached with the prestressing tools) on the concrete beam;

5. At the passive end, fasten the prestressing tool to the temporary anchor. At the active end, connect the prestressing tool to the hydraulic jack;

6. Pump the hydraulic jack to pull the prestressing tool on the active end until the load cell shows a force of $100 \mathrm{kN}$;

7. Tighten the locking nut on the active end and release the hydraulic jack. To be highlighted, the prestressing operation and releasing was completed within 10 minutes, which was considerably shorter than the epoxy adhesive pot life (e.g. about 30 minutes);

8. Leave the adhesive to cure for at least 24 hours as recommended;

9. Remove the prestressing tools after the curing of adhesive. In the experiment, the prestressing tool was removed after 6-day-curing due to the monitoring of the prestress loss;

The self-anchorage of the prestressed CFRP laminate was realized by implementing the stepwise prestressing method, see Figure 6. 


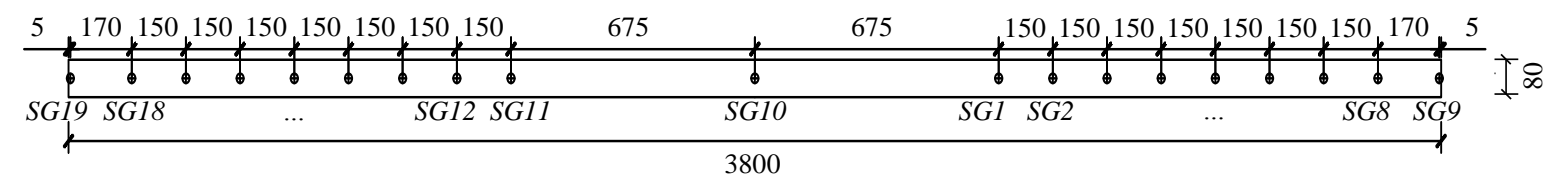

\section{Finite element analysis}

14 The finite element (FE) analysis in this study mainly covers the numerical simulation of two

Figure 6. Self-anchored prestressed CFRP laminate on the RC beam after removing the prestressing tool and temporary anchors

\subsection{Instrumentation and measurements}

To monitor the strain distribution and prestress loss, 19 strain gauges were installed along the CFRP laminate as illustrated in Figure 7. The locations of strain gauges were selected so that a strain gauge was placed between two subsequent tabs in the prestressing tool (see Figure 5). The strains were monitored during prestressing and 6 days after till the tool was detached from the beam. phases: (a) the prestressing process in which the force transfers through the prestressing tool to the CFRP laminate; and (b) the redistribution of the prestressing force between the CFRP laminate and the beam after removing the prestressing tool. The FE analysis aims to obtain a better understanding of the stress state in the concrete substrate and evaluate the effectiveness of the proposed method with regard to reducing interfacial stresses along the bond line.

\subsection{Modeling}

A two-dimensional (2D) shell model was developed using commercial FE package Abaqus ver. 6.14. With regard to the symmetry of the beam, only half of the specimen was modeled. All parts except the steel reinforcement bars and prestressing tool were modeled using $2 \mathrm{D}$ shell elements (CPS4R, plane stress). The longitudinal reinforcement bars and stirrups were modeled using truss elements (T2D2) embedded in the concrete. The prestressing tool was simply modeled using truss elements (T2D2) as links with distinct corresponding crosssectional area representing to the spring stiffness. Tie constraints were assigned to create surface-to-surface interactions between different parts including concrete/epoxy, epoxy/CFRP, CFRP/adhesive, and adhesive/connection plate. Node-to-node tie was defined between aluminum tabs and the connection plate to represent the bolted connection. The analysis defined 3 steps. In step 1, the adhesive layer was deactivated, and the prestressing force was 
1 applied to pull the tool; the same reaction force was defined on the concrete beam to simulate 2 the effect from the temporary anchor. In step 2, the adhesive layer was reactivated to simulate 3 the cured bond line. In step 3, the forces were suppressed to allow force redistribution between 4 the concrete and CFRP laminate to simulate the removal of prestressing tool. All materials 5 were assigned with linear elastic properties as mentioned in section 3.1.

\section{$65 \quad$ Results and discussion}

\section{$7 \quad 5.1 \quad$ Experimental results}

\section{$8 \quad 5.1 .1$ Distribution of tensile strain along the CFRP laminate}

9 The strain distribution was monitored along the laminate length during the prestressing process 10 and 6 days afterward. Figure 8 shows the distribution profile of tensile strains measured by 19 strain gauges at different prestressing levels. The effect of stepwise prestressing is demonstrated by gradually decreasing tensile strains over the anchorage length (i.e. $1250 \mathrm{~mm}$ ) from each end of the laminate.

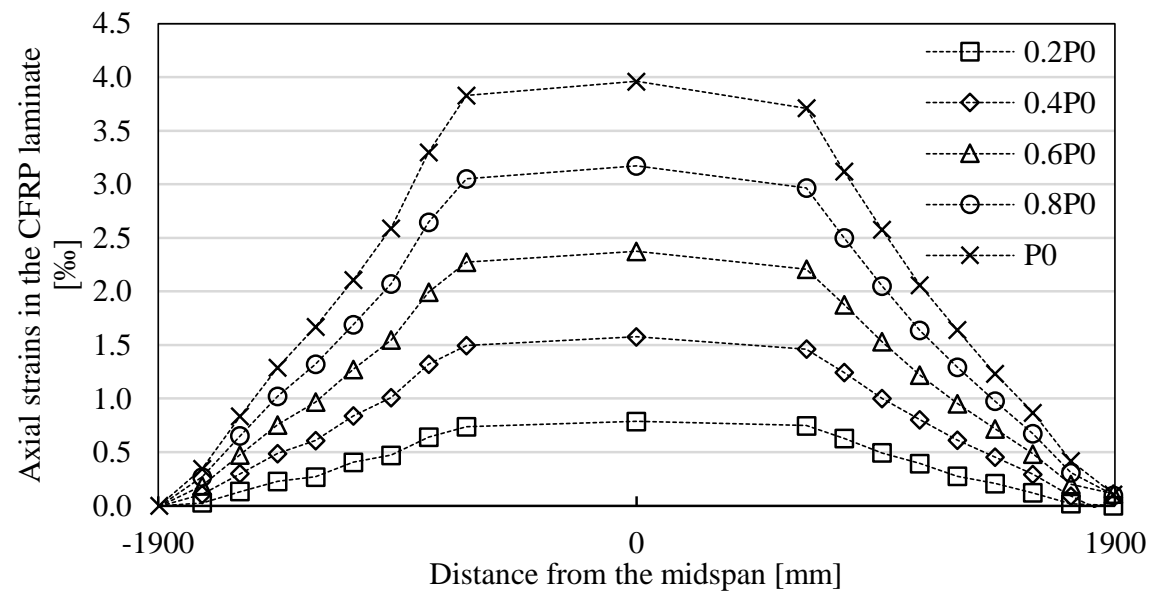

Figure 8. Tensile strains in the prestressed CFRP laminate measured by strain gauges during the prestressing process; $\mathrm{P}_{0}$ denotes the maximum prestressing force introduced to the CFRP.

\subsubsection{Loss of prestressing force during the curing of adhesive layer}

Pumping the hydraulic jack was stopped when the load cell displayed a force of $100 \mathrm{kN}$. At this moment, strain gauge SG10, located in the middle of CFRP, displayed a strain value equal to $3850 \mu$ strain equivalent to a force of $95.6 \mathrm{kN}$. The difference of $4.4 \mathrm{kN}$ in force is attributed to the friction in the prestressing tool. The slender concrete beam used in this study was slightly cambered as a result of prestressing. Inevitably, the guiding bars followed the slightly curved profile of the beam, which caused the friction between the tabs and guiding bars. After stopping pumping, the locking nut was tightened using a small wrench which increased the tensile strains in the laminate; and the strain in SG10 increased to $3960 \mu$ strain equivalents to $98.3 \mathrm{kN}$, see Figure 9.

The beam was then left at room temperature for 6 days to cure the epoxy adhesive as recommended by the supplier. Figure 9 demonstrates the variation of strains in the middle of the CFRP laminate (SG10) during the 6 days after tightening the locking nut. It shows that, during this period, the strain drops to $3610 \mu$ strain (equivalent to $89.6 \mathrm{kN}$ ), which is mainly attributed to a large extent of creep deformation in the concrete beam and a limited extent to 
at the midspan decreased by $8.8 \%$ (from $3960 \mu$ strain to $3610 \mu$ strain) after 48 hours and remained almost constant afterward. The corresponding prestressing level decreased by $2.7 \%$ from $31.1 \%$ to $28.4 \%$ of the CFRP laminate ultimate strength. Although the prestressing level became stable after 48 hours, $90 \%$ of the prestressing loss took place in the first 8 hours.

After 6 days, the locking nuts on both ends were released, and the prestressing tools removed. Subsequently, the strain value in SG10 reduced to $3481 \mu$ strain (equivalent to $86.4 \mathrm{kN}$ ) after removing the prestressing tool. The main reason for this drop is the change in the lever arm of prestressing force which switched from temporary anchor level to laminate level causing a secondary redistribution in the system. The overall prestressing loss in this experiment is considered acceptable given the geometry of the tested beam and great potential for creep.

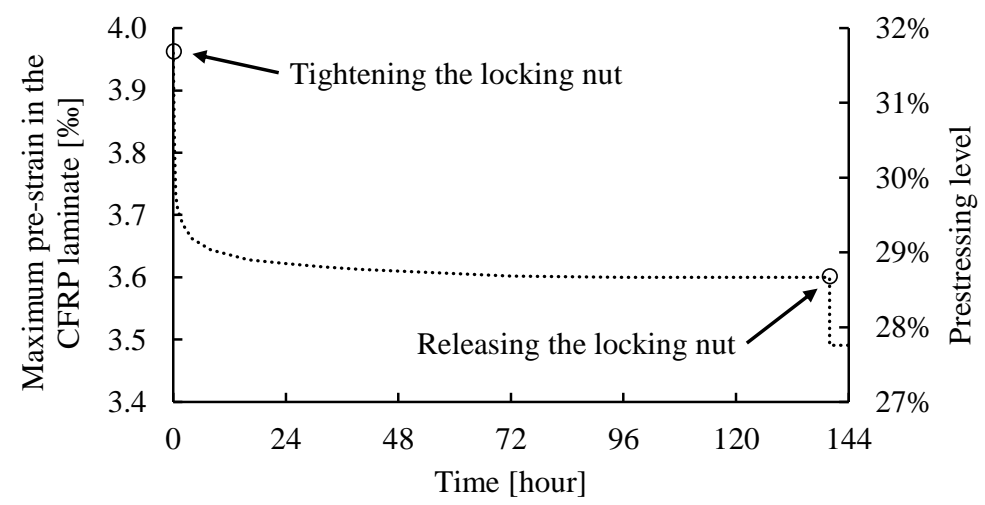

Figure 9. Variation of the strain in CFRP laminate at midspan during 144 hours after prestressing

\subsubsection{Interfacial shear stress in the bond line}

When the locking nut is released and the prestressing tool is demounted, the average interfacial shear stress along the bond line can be estimated using differential strains from subsequent strain gauges according to the equation Eq. 2 .

$$
\tau_{i}^{i+1}=\frac{\left(\varepsilon_{f, i+1}-\varepsilon_{f, i}\right) E_{C F R P} t_{C F R P}}{x_{i+1}-x_{i}}
$$

18 where $\tau_{i}^{i+1}$ is the average shear stress between SG i and SG (i+1); $E_{C F R P}$ is the modulus of the elasticity of the CFRP laminate; $t_{C F R P}$ is the thickness of the CFRP laminate; and $\left(x_{i+1}-x_{i}\right)$ is the distance between $S G i$ and $S G(i+1)$, e.g. $150 \mathrm{~mm}$ in this experiment. The interfacial shear stresses are presented in Figure 10, where $\tau_{\text {avg.interval }}$ represents the average interfacial shear stress at each interval from Equation 2. As can be seen, the maximum value of $\tau_{\text {avg.interval }}$ is less than $1.5 \mathrm{MPa}$, and the average value of $\tau_{\text {avg.interval }}$ over the anchorage length $L_{0}$ is $0.80 \mathrm{MPa}$ and $0.85 \mathrm{MPa}$ at each end. Assuming a constant distribution of the shear stress within each interval, the strength of the concrete becomes sufficient to resist the shear stress due to the transfer of the prestressing force from the CFRP laminate to the concrete beam. However, there exists a variation of shear stress at each interval. These variations are studied more accurately using FE method and the FE results are discussed in the following section. 


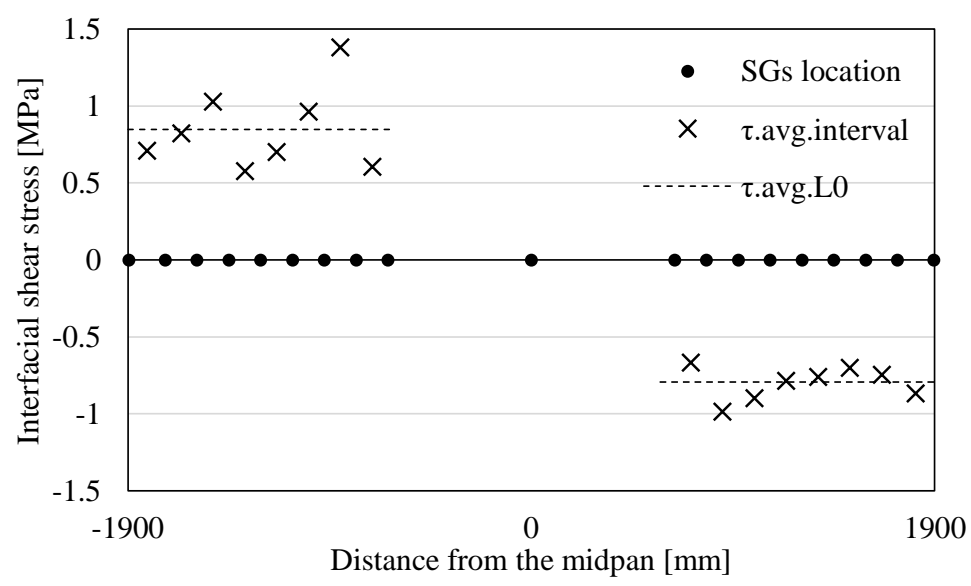

Figure 10. Average interfacial shear stress in the adhesive bond line after removing the prestressing system

\subsection{The FE results}

$5 \quad$ 5.2.1 Strain profile in the CFRP laminate after prestressing

6 At the end of prestressing process (i.e. fastening the locking nut), the tensile strain at the SG

710 reached a maximum value of $3960 \mu$ strain, which was equivalent to an axial force of 98.3

$8 \mathrm{kN}$ in the prestressed laminate. The same force was applied in the FE analysis at the end of the

9 prestressing tool to eliminate the effect of friction as explained earlier.

10 Figure 11 shows the strain profile along the CFRP, including FE results, experimental results 11 from strain gauges and results from the analytical solution based on axial stiffness of different 12 components in the prestressing system. Since the strain gauges are placed symmetrically with 13 respect to midspan, the strain gauge data in Figure 11 is presented according to the distance 14 from the midspan. The calculation of the analytical solution assumed full interaction (perfect 15 bond with no relative slip) between the CFRP laminate, the connection plate, and the 16 prestressing tool. Given a certain prestressing force $P_{0}$, the axial force in the CFRP over the 17 anchorage length could be calculated by the equation Eq. 3 .

$$
P_{C F R P}=\frac{(E A)_{C F R P}}{(E A)_{C F R P}+(E A)_{\text {connection plate }}+(E A)_{\text {spring }}} P_{0}
$$

Where $E A$ is the axial stiffness of each component of the prestressing system as shown in Figure 4. Figure 11 shows a good agreement between the FE and analytical results. However, they underestimate the strains in comparison to the experiment. This observation can be attributed to the fact that, in the FE analysis, the interaction between tabs and connection plate consists of a tie constrain coupling all degrees of freedom (full interaction). In reality, however, over-stressing in some steps (particularly at the bolted connections between tabs and connection plate close to the midspan) would result in local embedment damage in the connection plate and the slight change of the stiffness properties in that step. The overall adjustment of stiffness, apparently, acts in favor of a more uniform force distribution among different steps. 


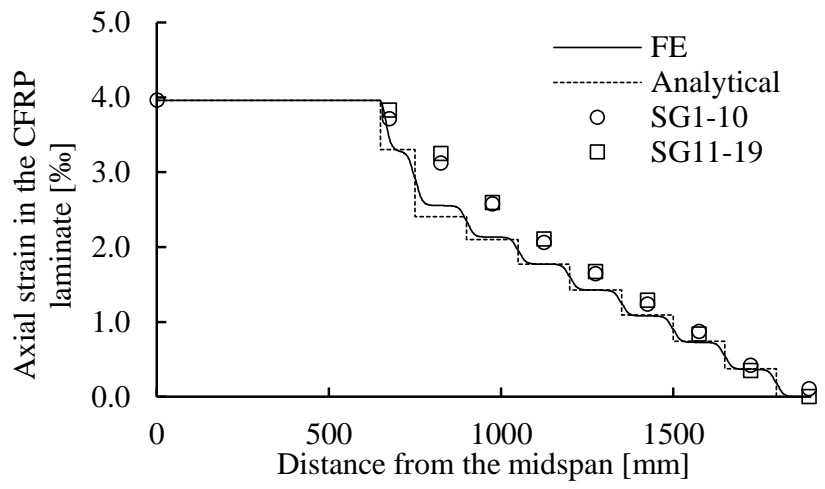

Figure 11. Tensile strain in the CFRP laminate using the stepwise prestressing method subjected to a maximum prestressing force of $98.3 \mathrm{kN}$

5.2.2 Interfacial stress along the bond line after removing the prestressing tool

Prior to the release of the locking nut, the prestressing force was concentrated and exerted to the beam at temporary anchors. Upon releasing the locking nut, the prestressing force transferred to the beam via the CFRP-concrete adhesive bond. This transfer was associated with the formation of interfacial shear stresses along the adhesive bond line. The FE analysis was used to study the interfacial stress along the bond line in more detail. To model the beam in a more realistic manner, the prestressing force assigned to the laminate in the FE model was calibrated according to the experimental results in order to represent the stressed state of the laminate in reality before releasing the locking nut; in specific, eight concentrated forces were applied along the laminate at the locations of the tabs. The magnitude of the forces was

$$
\begin{aligned}
& P_{\text {tab.i }}=\left(\varepsilon_{S G(i+1)}-\varepsilon_{S G i}\right)\left[(E A)_{C F R P}+(E A)_{\text {connection plate }}\right] \text { for } i=1 \text { to } 7 \\
& P_{\text {tab.8 }}=\varepsilon_{S G 10}(E A)_{C F R P}-\varepsilon_{S G 8}\left[(E A)_{C F R P}+(E A)_{\text {connection plate }}\right]
\end{aligned}
$$

Figure 12 shows the profile of the strain distribution before and after releasing the locking nut 19 from FE analysis together with experimental readings from strain gauges. As mentioned previously, upon the release of the locking nut, an internal force redistribution takes place in the system. As seen, the strain profile in the FE analysis after release matches well with the values from strain gauges (SG1-10 and SG11-19). The agreement assures reliable results on interfacial stresses along the bond line and in the concrete substrate calculated from the FE model. Figure 12 also reveals that the distribution of tensile strain does not significantly change before and after the release of the locking nut (difference less than 4\%) and the prestressing level within the anchorage length retains the expected stepwise profile and magnitude. 


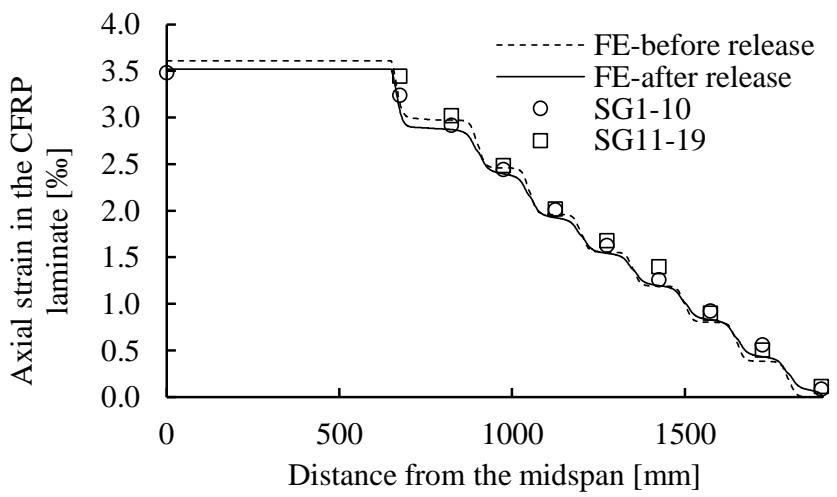

Figure 12. Axial strain profile in the CFRP laminate before and after releasing the locking nut according to the FE results and experimental measurements with strain gauges

Figure 13(a) shows the FE results after the release of the locking nut, including the strain profile along the CFRP laminate, the shear stress in the mid-thickness of the adhesive layer between concrete and CFRP, and the shear stress in the concrete, $1 \mathrm{~mm}$ beneath the concrete-epoxy interface. The magnitude of peak interfacial shear stress at the mid-thickness of the epoxy later within the anchorage length ranges between $1.8 \mathrm{MPa}$ and 2.6 MPa, which occur at the location of tabs. The concrete substrate is the weak link in the bonded joint. Therefore, it would be interesting to study the magnitude of shear stress inside the concrete just below the adhesive layer. As shown in Figure 13(a), the shear stress, $1 \mathrm{~mm}$ beneath the concrete surface, has a peak value of about $0.9 \mathrm{MPa}$. The reduced interfacial shear stress in the concrete lays the foundation for the self-anchorage of the CFRP laminate after removing the prestressing tool. The magnitude of the peeling (normal) stress is smaller compared to shear stress along the anchorage length and ranges between $-0.1 \mathrm{MPa}$ to $0.1 \mathrm{MPa}$, see Figure 14(a). Except for the critical location (650 $\mathrm{mm}$ from the midspan) where the GFRP connection plate is terminated, the peeling stress reaches the maximum peak values at the end of the CFRP-concrete bond, where the maximum peeling stresses are $1.5 \mathrm{MPa}$ and $0.5 \mathrm{MPa}$ in the adhesive layer and $1 \mathrm{~mm}$ beneath the concrete surface, respectively. As a result, the maximum principal stress as shown in Figure 14(b) yields to $2.7 \mathrm{MPa}$ and 1.2 MPa in the adhesive layer and concrete, respectively, at the end of the bonded CFRP laminate.

To evaluate safety margin of the CFRP-concrete bond, the local bond strength $\tau_{\text {max }}$ is calculated using the equation Eq. 5 proposed by Lu et al. [28], which is the function of concrete strength and geometry of the bond. The bond strength $\tau_{\max }$ of the investigated specimen is estimated to be $5.7 \mathrm{MPa}$ using this equation.

$$
\tau_{\text {max }}=1.50 f_{c t} \sqrt{\frac{2.25-b_{C F R P} / b_{c}}{1.25+b_{C F R P} / b_{c}}}
$$

Where $f_{c t}$ is the tensile strength of the aged concrete $\mathrm{C} 35 / 45 ; b_{C F R P}$ and $b_{c}$ are the width of the CFRP laminate and the concrete beam, respectively. Compared to the local bond strength, the peak interfacial shear stress of $0.9 \mathrm{MPa}$ accounts for $16 \%$ of the bond capacity, representing a good margin of safety. 

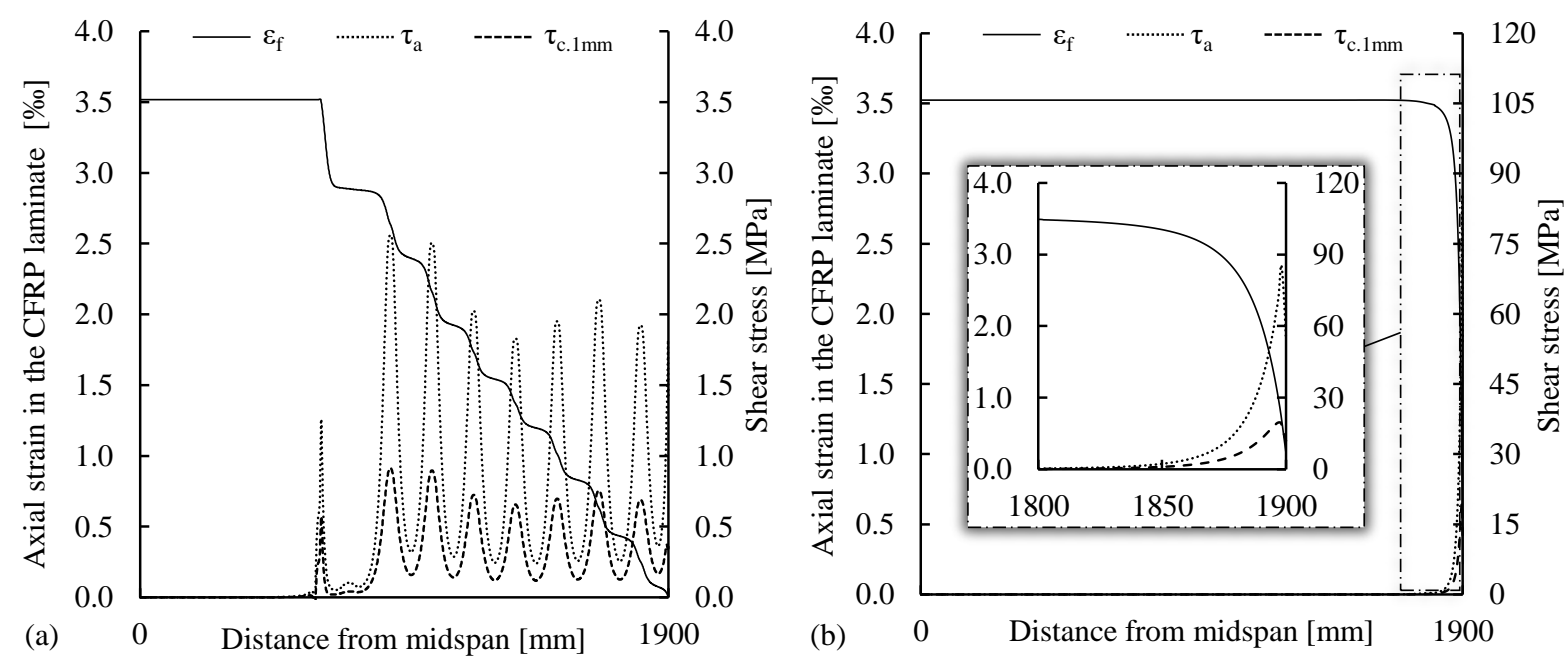

2 Figure 13. FE results based on the modeling of (a) stepwise prestressing method and (b) conventional prestressing method, 3 including the axial strain in the CFRP laminate after releasing the locking nut $\varepsilon_{f}$, the shear stress in the adhesive layer $\tau_{a}$, and

$41 \mathrm{~mm}$ beneath the concrete surface $\tau_{c .1 \mathrm{~mm}}$.
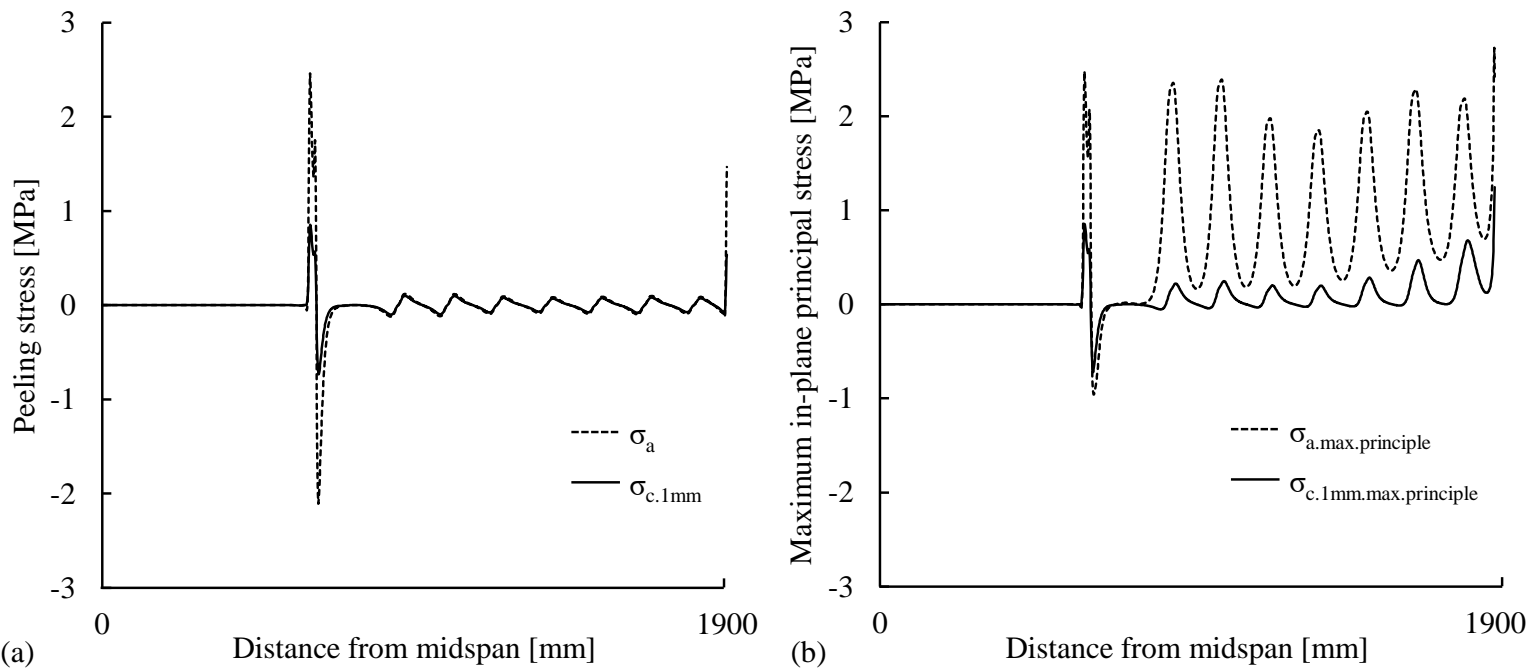

Figure 14. FE results of the stepwise prestressing method regarding (a) the peeling stress and (b) maximum principal stress in the adhesive layer and $1 \mathrm{~mm}$ beneath the concrete surface

\section{$8 \quad 5.3$ Effectiveness of stepwise prestressing system}

9 In conventional prestressing systems, the CFRP laminate is pulled from a point (usually the 10 laminate end). In this manner, a uniform axial force would be created along the laminate length. After removing the prestressing force, large interfacial stress would be built up in bond line at areas close to laminate ends which eventually cause laminate debonding in the absence of mechanical anchorage [14]. To evaluate the effectiveness of the novel stepwise prestressing system, it would be interesting to compare the interfacial shear stresses in the two prestressing methods subjected to the same level of prestressing force. Figure 13(b) shows the FE results from the conventional prestressing method with regard to the tensile strain in the laminate and shear stress in the adhesive layer and concrete after the release of the prestressing force. The sudden drop of the tensile strain in the CFRP close to the end of laminate indicates a short anchorage length of about $100 \mathrm{~mm}$, which is associated with significant high shear stress in the concrete substrate (ca. $20 \mathrm{MPa}$ at $1 \mathrm{~mm}$ beneath the concrete surface). In contrast, the stepwise prestressing system results in the peak shear stress as low as $0.9 \mathrm{MPa}$, which renders a 
1 significant reduction of 22 times. It is observed that the stepwise prestressing method extends 2 the anchorage length from approximately $100 \mathrm{~mm}$ in the conventional prestressing to $1250 \mathrm{~mm}$.

3 It should be noted that the area under the shear stress curve in both cases is the same since the 4 total prestressing forces are equal.

\section{Conclusions}

6 This paper investigated the efficiency of a novel method to prestress CFRP laminates used as externally bonded reinforcement using numerical and experimental approach. The innovative feature of the proposed prestressing method is to eliminate the need for mechanical anchorage and realize the self-anchorage of the laminate after removing the prestressing system.

Results indicate that the proposed method provides a gradual transfer of the prestressing force from the CFRP laminate to the concrete beam. As a result, the interfacial stresses along the bond line can be reduced below the strength of the concrete substrate to realize the selfanchorage of the prestressed laminate. Results from FE analyses indicate that peak interfacial shear stresses, as low as $2.6 \mathrm{MPa}$ in the adhesive layer and $0.9 \mathrm{MPa}$ in the concrete substrate, occur in the CFRP-concrete adhesive joint given a maximum prestressing force of $90 \mathrm{kN}$ in the bonded CFRP laminate. The shear stress in the concrete substrate accounts for $16 \%$ of the local CFRP-concrete bond strength, which ensures the safe self-anchorage of the prestressed laminate. Overall, the proposed method is considered practical with respect to application time and straightforward procedure. Although this paper presents the application of this technique for strengthening of reinforced concrete beams, the method has the potential for strengthening steel girders, where the conventional mechanical anchors involves drilling holes in flanges which is not desirable from fatigue performance point of view.

\section{Acknowledgment}

The work in the paper is a part of SUREBridge (Sustainable Refurbishment of Existing Bridges) project which has received funding from the European Union's Seventh Framework Programme for research, technological development and demonstration. The SUREBridge project is co-funded by Funding Partners of the ERA-NET Plus Infravation program.

\section{References}

[1] Motavalli M, Czaderski C, Pfyl-Lang K. Prestressed CFRP for Strengthening of Reinforced Concrete Structures: Recent Developments at Empa, Switzerland. J Compos Constr 2011;15:194-205. doi:10.1061/(ASCE)CC.1943-5614.0000125.

[2] André A, Haghani R, Biel A. Application of fracture mechanics to predict the failure load of adhesive joints used to bond CFRP laminates to steel members. Constr Build Mater 2012;27:331-40. doi:10.1016/j.conbuildmat.2011.07.040.

[3] Ghafoori E, Hosseini A, Al-Mahaidi R, Zhao X-L, Motavalli M. Prestressed CFRPstrengthening and long-term wireless monitoring of an old roadway metallic bridge. Eng Struct 2018;176:585-605. doi:10.1016/j.engstruct.2018.09.042.

[4] Kliger R, Haghani R, Brunner M, Harte AM, Schober K-U. Wood-based beams strengthened with FRP laminates: improved performance with pre-stressed systems. Eur J Wood Wood Prod 2016;74:319-30. doi:10.1007/s00107-015-0970-5.

[5] Heshmati M, Haghani R, Al-Emrani M. Durability of CFRP/steel joints under cyclic wetdry and freeze-thaw conditions, Composites Part B, 2017, 126:211-226.

[6] Ali A, Abdalla J, Hawileh R, Galal K. CFRP mechanical anchorage for externally strengthened RC beams under flexure, 2014, Physics Procedia, 55:10-16. 
[7] Teng J, Chen J, Smith S, Lam L. Behaviour and strength of FRP-strengthened RC structures: a state-of-the-art review. Proc ICE- Struct Build 2003:51-62. doi:10.1680/stbu.2003.156.1.51.

[8] Triantafillou TC, Deskovic N. Innovative Prestressing with FRP Sheets: Mechanics of Short-Term Behavior. J Eng Mech 1991;117:1652-72. doi:10.1061/(ASCE)07339399(1991)117:7(1652).

[9] Meier U. Strengthening of structures using carbon fibre/epoxy composites. Constr Build Mater 1995;9:341-51. doi:10.1016/0950-0618(95)00071-2.

[10] Garden HN, Hollaway LC. An experimental study of the failure modes of reinforced concrete beams strengthened with prestressed carbon composite plates. Compos Part B Eng 1998;29:411-24. doi:10.1016/S1359-8368(97)00043-7.

[11] Quantrill RJ, Hollaway LC. The flexural rehabilitation of reinforced concrete beams by the use of prestressed advanced composite plates. Compos Sci Technol 1998;58:1259-75. doi:10.1016/S0266-3538(98)00002-5.

[12] Aslam M, Shafigh P, Jumaat MZ, Shah SNR. Strengthening of RC beams using prestressed fiber reinforced polymers - A review. Constr Build Mater 2015;82:235-256. doi:10.1016/j.conbuildmat.2015.02.051.

[13] Haghani R. Analysis of adhesive joints used to bond FRP laminates to steel members - A numerical and experimental study. Constr Build Mater 2010;24:2243-51. doi:10.1016/j.conbuildmat.2010.04.032.

[14] Triantafillou TC, Deskovic N, Deuring M. Strengthening of concrete structures with prestressed fiber reinforced plastic sheets. ACI Struct J 1992;89:235-44.

[15] Kalfat R, Al-Mahaidi R, Smith ST. Anchorage Devices Used to Improve the Performance of Reinforced Concrete Beams Retrofitted with FRP Composites: State-of-the-Art Review. J Compos Constr 2013;17:14-33. doi:10.1061/(ASCE)CC.1943-5614.0000276.

[16] Kim YJ, Wight RG, Green MF. Flexural Strengthening of RC Beams with Prestressed CFRP Sheets: Development of Nonmetallic Anchor Systems. J Compos Constr 2008;12:35-43. doi:10.1061/(ASCE)1090-0268(2008)12:1(35).

[17] Kim YJ, Wight RG, Green MF. Flexural Strengthening of RC Beams with Prestressed CFRP Sheets: Using Nonmetallic Anchor Systems. J Compos Constr 2008;12:44-52. doi:10.1061/(ASCE)1090-0268(2008)12:1(44).

[18] Grelle SV, Sneed LH. Review of Anchorage Systems for Externally Bonded FRP Laminates. Int J Concr Struct Mater 2013;7:17-33. doi:10.1007/s40069-013-0029-0.

[19] Stöcklin I, Meier U. Strengthening of concrete structures with prestressed and gradually anchored CFRP strips. FRPRCS-5 Fibre-Reinf. Plast. Reinf. Concr. Struct. Vol. 1, Thomas Telford Publishing; 2001, p. 291-6. doi:10.1680/frprcsv1.30299.0030.

[20] Michels J, Sena-Cruz J, Czaderski C, Motavalli M. Structural Strengthening with Prestressed CFRP Strips with Gradient Anchorage. J Compos Constr 2013;17:651-61. doi:10.1061/(ASCE)CC.1943-5614.0000372.

[21] Kotynia R, Walendziak R, Stoecklin I, Meier U. RC Slabs Strengthened with Prestressed and Gradually Anchored CFRP Strips under Monotonic and Cyclic Loading. J Compos Constr 2010;15:168-80. doi:10.1061/(ASCE)CC.1943-5614.0000081.

[22] Czaderski C, Motavalli M. 40-Year-old full-scale concrete bridge girder strengthened with prestressed CFRP plates anchored using gradient method. Compos Part B Eng 2007;38:878-86. doi:10.1016/j.compositesb.2006.11.003.

[23] Haghani R, Al-Emrani M, Kliger R. A new method for strengthening concrete structures using prestressed FRP laminates. Proceeding 8th Int. Struct. Eng. Constr. Conf., 2015, p. 1153-8. 
[24] Haghani R, Al-Emrani M, Kliger R. Interfacial stress analysis of geometrically modified adhesive joints in steel beams strengthened with FRP laminates. Constr Build Mater 2009;23:1413-22. doi:10.1016/j.conbuildmat.2008.07.013.

[25] Reed MW, Barnes RW, Schindler AK, Lee H-W. Fiber-Reinforced Polymer Strengthening of Concrete Bridges that Remain Open to Traffic. Struct J 2005;102:82331. doi:10.14359/14790.

[26] ASTM International. ASTM D3039/D3039M-17 Standard Test Method for Tensile Properties of Polymer Matrix Composite Materials. West Conshohocken, PA: ASTM International; 2017.

[27] Heshmati M, Haghani R, Al-Emrani M. Durability of bonded FRP-to-steel joints: Effects of moisture, de-icing salt solution, temperature and FRP type. Compos Part B Eng 2017;119:153-67. doi:10.1016/j.compositesb.2017.03.049.

[28] Lu XZ, Teng JG, Ye LP, Jiang JJ. Bond-slip models for FRP sheets/plates bonded to concrete. Eng Struct 2005;27:920-937. doi:10.1016/j.engstruct.2005.01.014. 